\title{
About Trypanosoma brucei gambiense, the causative agent of the chronic form of Human African Trypanosomiasis: some findings and proposals
}

\author{
P. Truc ${ }^{1,2}$ \\ ${ }^{1}$ Organisation de Coordination pour la lutte contre les Endémies en Afrique Centrale (OCEAC), Department of Research \\ and Control of Human African Trypanosomiasis, BP 288, Yaounde, Cameroon. \\ ${ }^{2}$ Institut de Recherche pour le Développement, IRD, Research Unit 35 BP 1857, Yaounde, Cameroon. E-mail: \\ truc@iccnet.cm, Tel: + 2379846057.
}

Accepted 20 November 2003

\begin{abstract}
Since its discovery at the beginning of 20th century, Human African Trypanosomiasis or sleeping sickness has killed several hundred thousands of individuals in Africa, mainly in Central part of the continent. The actual situation of the disease in several countries is dramatic, such as in Sudan, Democratic Republic of Congo or Angola. However, diagnosis is still based on the detection of parasites in blood or lymphatic juice by microscopy, like in 1930's. Furthermore, since the discovery of melarsoprol in 1949, no novel drugs have been synthesized for treatment. This must consider it within the whole context of "most-neglected diseases" but some findings obtained through biotechnology are discussed in terms of epidemiology and control applications.
\end{abstract}

Key words: Human African Trypanosomiasis, neglected disease, biotechnologies.

Nowadays, sleeping sickness or Human African Trypanosomiasis (HAT) is considered to be one of "the most-neglected diseases", in terms of drug development and continues to plague Africa (Morel, 2003). World Health Organization estimates that about 600,000 persons are currently infected, most of them in Central Africa. The chronic form of HAT is a lethal disease caused by a parasite named Trypanosoma brucei gambiense. This parasite is transmitted by vector, tsetse flies, most of which belong to the species Glossina palpalis. Since the discovery of this pathology at the beginning of $20^{\text {th }}$ century (e.g. Bruce and Nabarro, 1903), HAT has killed several hundred thousands of individuals in Africa, mainly in Central part of the continent (Martin et al., 1909; W.H.O., 1998). Although the epidemic of 19201930 's was successfully controlled thanks to Dr. Jamot 
and mobile medical teams surveys, especially in Cameroon between 1928 and 1930, the actual situation of the disease in several countries is dramatic, such as in Sudan, Democratic Republic of Congo or Angola. Many research teams have tried to improve our knowledge of the epidemiology, pathogenicity and genetics of HAT for about 40 years, using sophisticated tools for diagnosis, isolation and characterization of trypanosomes. However, the absence of operational therapeutic alternatives appears to be in contradiction with all the research activities mentioned above (this list is not exhaustive unfortunately). Thus, although biotechnologies are useful, for example, to confirm different pathogenic forms of HAT (genetic distinction between $T$. b. gambiense and $T . b$. rhodesiense, the agent of acute form of the disease), the existence of an animal reservoir, the identification of infected flies, most of the current knowledge on the epidemiology of HAT was known 70 years ago (see Mulligan, 1970). Moreover, diagnosis is still based on the detection of parasites in blood or lymphatic juice by microscopy, as during the time of Dr. Jamot in 1930's. Indeed, about 70 years ago, HAT specialists already knew that a chronic form occurred in West and Central Africa while an acute form was spreading in East Africa. Even the main drug used by Dr. Jamot, Tryparsamide, was chemically an arsenic derivative, like melarsoprol, discovered by Friedheim in 1949 (see Dumas et al., 1999). Since then, few novel drugs have synthesized, mostly chance discoveries of compounds initially intended to treat cancer, Ornidyl (DIdifluoromethylornithine) or Chagas disease, Lampit (nifurtimox). Both of these drugs are used for the treatment of second stage of HAT or after treatment failure when using melarsoprol (see the review by Van Nieuwenhove, 1999).

This is reality, but we must consider it within the whole context of "most-neglected diseases" and discuss some findings obtained through biotechnology. A review on this subject has been published by Dumas and colleagues (1999). Drugs and therapy will not be discussed because since the introduction of Atoxyl in 1904, the ideal antitrypanosomal drug, which is cheap, effective in early and advanced sleeping sickness, of low toxicity, with a long duration of action after oral absorption and not rapidly inducing resistance, has yet to be discovered (Van Nieuwenhove, 1999). While some new diamidines (e.g. DB 289, Brun, personal communication), and combination therapy are under study, none of these is yet operational for treatment. Two issues of research will be discussed: first concerning mass screening, diagnostic and stage determination of patients, second about the epidemiology of the disease (e.g. isolation, biology and genetic of trypanosomes).

In 1978, the Card Agglutination Test for Trypanosomiasis (CATT/T. b. gambiense; Magnus et al., 1978) was described. If positive, agglutination was observed due to the presence of anti-trypanosome antibodies in blood. Therefore, CATT/T. b. gambiense allowed mass screening, but parasite detection was required in blood or lymph node aspirate. Today, the $\mathrm{CATT/T}$. b. gambiense is the usual test for mass screening, but its specificity is low because false positive results caused by others pathologies such as malaria. $\mathrm{CATT} / T$. b. gambiense is still being evaluated despite many previous studies and simplification of this test or alternative version such as a version using Latex monoclonal antibodies or a micro-method using filter paper for blood collection named micro-CATT (e.g. Jamonneau et al., 2000c; Truc et al., 2002a). Again, considering the lack of new drugs and despite improvement of diagnosis tools for many other diseases, $\mathrm{HAT} / T$. b. gambiense diagnosis is still based on parasite detection like in 1930's.

The use of the anion exchange cellulose chromatography was a major finding for studying trypanosomes (Lanham and Godfrey, 1970). Indeed, the low number of bloodstreams forms (BSF) ( $T$. $b$. gambiense) and their low virulence when inoculated to rodents were limiting factors for biological and genetic studies. Although chromatography was used for concentration of trypanosomes from blood, it has been adapted for diagnosis in the field (miniature anionexchange centrifugation technique, mAECT; Lumsden et al., 1979). The mAECT is used in several countries. Before 1979, the traditional techniques for microscopic examination of blood for trypanosomes detection were based on thin, wet or thick blood films with a sensitivity of 33-17 trypanosomes per $\mathrm{ml}$ of blood, while mAECT detected 3-4 trypanosomes per ml of blood. An individual is declared infected by sleeping sickness when parasite is detected either in blood or lymph node aspirate (WHO, 1998). Thus, a better detection of parasites using mAECT was a major improvement for control activities. Other concentration techniques were proposed, such as Capillary Tube Centrifugation technique or CTC (Woo, 1970), the Quantitative Buffy Coat or QBC (Bailey and Smith, 1992) but, unfortunately, some national control programs in Africa can only perform microscopic examination of thick or wet blood films for financial reasons and/or lack of appropriated equipment. Again, discordance exists, unfortunately, between biotechnology and techniques used for control activities. This could partially explain why HAT is considered to be one of the "most-neglected diseases".

Following the infective bite by tsetse fly, the classical clinical evolution of HAT in human starts with the haemato-lymphatic or first stage (P1), characterized by only few typical clinical signs (primary lesion or chancre, swollen lymph node or Winterbottom's sign). Then, the meningo-encephalitic or second stage (P2) occurs due to the presence of trypanosomes in the cerebrospinal fluid (CSF), leading to the progressive appearance of 
neurological disorders. The classical stage determination method is based on CSF cell counting (cut-off, 5 cells $/ \mu \mathrm{l}$ ), CSF protein concentration (cut-off, $37 \mathrm{mg} / 100 \mathrm{ml}$ by the dye-binding protein assay) and/or the presence of trypanosomes detected by simple or double centrifugation of CSF (WHO, 1998). However the cut-off values and the sensitivity of detection of trypanosomes in CSF remain doubtful (Truc et al., 1999). On the other hand, clinical examination for detection of neurological disorders may contribute to detect a second stage of the disease but is not satisfactory either (Bisser et al., 2000). However, the appropriate treatment depends on the accurate determination of disease stage. Indeed, for the chronic form caused by $T$. b. gambiense, the treatment of patients in stage P1 is pentamidine while melarsoprol is used for stage P2. Because of toxicity and severe, potentially fatal side effects of melarsoprol and the possibility to cure some $\mathrm{P} 2$ patients using pentamidine (Doua et al., 1996), stage determination must be highly accurate. Recently, new biological markers for parasite detection in the CSF have been discovered. For example, specific IgM antibodies (Latex/lgM: Lejon et al., 1998, 2002, Büscher et al., 1999) and anti-galactocerebroside antibodies in CSF produced in response to the progressive demyelinating process triggered by the presence of trypanosomes in the cerebral environment (Bisser et al., 2000). However, these techniques and others such as parasite DNA detection in CSF by PCR based methods are not yet ready for a routine use. Indeed, PCR is yet unrealistic for a field use, and the cutoff value for positive result of Latex/lgM is unknown. Therefore, stage determination is partially based on parasite detection in CSF, like in 1930's. This confirms again the gap between un-appropriated tools for control activities and products of the new technologies.

Isolation of BSF of $T$. b. gambiense is difficult in field conditions because of low parasitaemia in blood and low virulence of these parasites when inoculated in experimental rodents (see Gibson et al., 1999). However, $\mathrm{BSF}$ are required for different research purposes, such as studies on population genetic or identification of hosts. Thus, an adaptation and simplification of the procedure using anion-exchange centrifugation (Lanham \& Godfrey, 1970) was described (Truc et al., in press). The objective was to concentrate and freeze in field conditions a high number of BSF from patients. On the other hand, the isolation of procyclic forms of $T$. b. gambiense from mammals has been improved thanks to the KIVI (Kit for In Vitro Isolation of trypanosomes, Aerts et al., 1992). Its efficiency was demonstrated, both for $T$. $b$. gambiense from humans (Truc et al., 1992), T. brucei spp. and T. congolense from domestic and wild animals (Oka Komoin et al., 1994). However, its value as operational diagnostic test has been controversed (Mc Namara et al., 1995). Indeed, KIVI cannot be used as a tool for quick parasite detection in the field because of the delay for culture to become positive. Again, the mAECT remains the most useful technique for diagnostic of HAT, when available.

The genetic identification of trypanosomes was performed first by Multi-Locus Enzyme Electrophoresis MLEE (Godfrey and Kilgour, 1976, Gibson et al., 1980). Restriction Fragment Length Polymorphism of kinetoplast DNA has been also used to distinguish stocks of T.b. gambiense from other sub-species (e.g. Borst et al., 1980). For MLEE, several protocols were described, using either starch or acetate gel, studying a range of metabolic enzymes called isoenzymes (e.g. Gibson et al, 1980, Truc et al., 1991). A recent short review has been published about molecular biology and identification of trypanosomes (Truc and Cuny, 2000). The ancestral taxonomy distinguished $T$. b. gambiense (agent of the chronic form in West and Central Africa), $T . \quad b$. rhodesiense (agent of the acute form in East Africa) and $T$. b. brucei, agent of the "nagana" in cattle and pathogenic for others animals but non-infective for human. This classification was partially confirmed by genetic analysis. Indeed, isoenzyme results indicated that T. b. gambiense was almost homogeneous (group 1: Gibson, 1986) but some strains did not fit into this group 1 and were suspected to be more pathogenic (Truc et al., 1997). Furthermore, the pathogenicity of trypanosomes and their corresponding genetic identification did not confirm the existence of only a chronic form of HAT in West Africa (Jamonneau et al., 2000, a, b, 2002). While $T$. b. gambiense was clearly separated from $T$. $b$. rhodesiense, sub-groups were described within $T$. $b$. rhodesiense as specific of a given geographical location such as busoga group (see Gibson et al., 1999). On the other hand, genetic analysis indicated that $T . b$. brucei was closely related to $T$. $b$. rhodesiense. The hypothesis of a common ancestor for both $T$. b. rhodesiense and $T$. b. brucei was mentioned (see Gibson et al., 1999). But these findings did not change control against HAT, excepted in cases of overlap of $T$. b. gambiense and $T$. $b$. rhodesiense foci, such as in Uganda or Kenya. More sophisticated techniques, such as PCR based methods, confirmed isoenzyme findings with even more distinction within each sub-species (e.g. RAPD). Furthermore, the use of microsatellite markers allowed to evidence coinfection by different genotypes in the same patient (Truc et al., 2002b). Consequences of co-infection may be important and justify in part the genotype selection detected by the isolation method (Jamonneau et al., 2003). Hence, it should be a strong assumption that most of strains studied were only part of the real natural populations of trypanosomes infecting patients. Thus, a bias might be introduced in many studies for which parasite isolation and identification are required, such as genetic or drug sensitivity assays. New procedures must be set up to avoid isolation and selection of trypanosomes in vivo or in vitro in order to get reliable results considering the natural diversity of wild 
trypanosomes populations. For instance, trypanosomes in body fluids could be used to amplify particular genes of parasite DNA (such as a gene involved in resistance to drug). An alternative would be to induce cloning and reproduction of individual trypanosome freshly collected from patient, animal or tsetse fly. This is unrealistic at the moment for technical reasons but must be seriously investigated as soon as possible.

Another interest of genetic identification of parasite was confirmation of the clonal mode of reproduction (Tibayrenc et al., 1990), propagation of HAT (Truc and Cuny, 2001), distribution in space and time (endemic or epidemic, Truc and Tibayrenc, 1993), suspicion of an animal reservoir of parasites (e.g. Gibson et al., 1978, 1980; Mehlitz et al., 1982; Truc et al., 1991, 1997; Truc and Tibayrenc, 1993). Isoenzymes and other genetic markers indicated that trypanosomes circulating in animals are similar to those found in human. Thus domestic animals turn to be a putative animal reservoir of HAT. For this latter point, it is only a presumption because no evidence was given about an active role of the animal reservoir in transmission of HAT to human. Moreover, the role of the animal reservoir for the chronic form might be protective for the human population. Indeed, where animals are infected by $T$. b. gambiense, the prevalence in human population is low, as for example in Côte d'Ivoire or Cameroon. In the particular case of Cameroon, the situation of HAT is remarkable. Indeed, while 400.000 persons were diagnosed and cured in 1930's and campaigns of prophylaxy maintained until the 1960's, no outbreak was noticed despite persistence of endemic foci and tsetse flies. This is surprising when comparing with the bordering countries such as Chad, Congo or Central African Republic where outbreaks are occurring in several foci since over 20 years. Such particular case of Cameroon must be investigated.

Other new techniques have been very useful for studying vector behaviour. Indeed, MLEE allowed to distinguish human or non-human origin of tsetse blood meals (Diallo et al., 1997). This blood meals analysis was improved by Heteroduplex analysis, a PCR based method (Boakye et al., 1999). Thus, knowledge of contact between vectors and human or animal was improved, leading to a better understanding of the risk of transmission of HAT. This was confirmed by the identification of trypanosomes in vector (Masiga et al., 1996).

Some operational tools may improve HAT control, and new technologies allowed to explain some aspects of the epidemiology of HAT, through a better knowledge of the biology and taxonomy of trypanosomes. However, diagnosis is still based on parasite detection like in 1930's. It is urgent to improve tools for mass screening, diagnosis and stage determination for a field routine use. Furthermore, PCR based method protocols must be adapted for studying trypanosomes using body fluids without trypanosomes isolation in vivo or in vitro. Thus, we may have a better identification of natural populations of parasites infecting patients (and animals), because mixed or co-infections should be evidenced. Studies on taxonomy, biology or drug sensitivity of $T$. b. gambiense would be then more reliable.

\section{REFERENCES}

Aerts D, Truc P, Penchenier L, Claes Y, Le Ray D (1992). A kit for in vitro isolation of trypanosomes in the field: First trial with sleeping sickness patients in the Congo Republic. Trans. R. Soc. Trop. Med. Hyg. 86 : 394-395.

Bailey J, Smith DH (1992). The use of the acridine orange QBC technique in the diagnosis of African trypanosomiasis. Trans. R. Soc. Trop. Med. Hyg. 86: 630.

Bisser S, Ayed Z, Bouteille B, Stanghellini A, Breton JC, Dumas M, Jauberteau MO (2000). Central nervous system involvment in African trypanosomiasis: presence of anti-galactocerebroside antibodies in patients cerebrospinal fluid. Trans. R. Soc. Trop. Med. Hyg. 94 : 225226 .

Boakye D, Tang J, Truc P, Merriweather A, Unnasch T (1999). Identification of blood meals in hematophagous Diptera by polymerase chain reaction and heteroduplex analysis. Med. Vet. Entomol. 13 : 282-287.

Borst P, Fase Fowler F, Hoeijmakers JHJ, Frasch ACC. (1980). Variations in maxi-circle and mini-circle sequences in the kinetoplast DNAs from different Trypanosoma brucei strains. Biochem. Biophys. Acta 610: 197-210.

Bruce D, Nabarro D (1903). Progress report on sleeping sickness in Uganda. Royal Society Sleeping Sickness Commission Reports 2: 10-88.

Büscher P, Lejon V, Magnus E, Van Merveinne N (1999). Improved latex agglutination test for detection of antibodies in serum and cerebrospinal fluid of Trypanosoma brucei gambiense infected patients. Acta Trop. 73 : 11-20.

Diallo P B, Truc $P$, Laveissière $C$ (1997). A new method for identifying blood meals of human origin in tsetse flies. Acta Trop. $63: 61-64$.

Doua F, Miézan TW, Sanon Singaro JR, Boa Y, Baltz T (1996). The efficacy of pentamidine in the treatment of early-late stage Trypanosoma brucei gambiense trypanosomiasis. Am. J. Trop. Med. Hyg. 54 : 163-168.

Dumas M, Bouteille B, Buguet A (1999). Progress in Human Africa Sleeping sickness. Springer Publ. Ed., Paris.

Gibson WC (1986). Will the real Trypanosoma brucei gambiense please stand up? Parasitol. Today 2: 255-257.

Gibson WC, Borst P, Fase-Fowler F (1985). Further analysis of intraspecific variation in Trypanosoma brucei using restiction site polymorphisms in the maxi-circle of kinetoplast DNA. Mol. Biochem. Parasitol. 15: 21-36.

Gibson WC, Marshall TF, Godfrey DG (1980). Numerical analysis of enzyme polymorphism: a new approach to the epidemiology and taxonomy of trypanosomes of subgenus Trypanozoon. Adv. Parasitol. 18: 175-246.

Gibson WC, Mehlitz D, Lanham S, Godfrey DG (1978). The identification of Trypanosoma brucei gambiense in Liberian pigs and dogs by isoenzymes and by resistance to human plasma. Tropenmed. Parasitol. 29: 335-345.

Gibson WC, Stevens JR, Truc P (1999). Identification of trypanosomes: from morphology to molecular biology. In: "Progress in Human African Trypanosomiasis sleeping sickness", Editors M. Dumas, B. Bouteille, A. Buguet, Springer Publ., Paris, pp. 7-29.

Godfrey DG, Kilgour V (1976). Enzyme electrophoresis in characterizing the causative organism of Gambian trypanosomiasis. Trans. R. Soc. Trop. Med. Hyg. 70: 219-224.

Jamonneau V, Barnabé C, Koffi M, Sané B, Cuny G, Solano P (2003). Identification of Trypanosoma brucei circulating in a sleeping 
sickness focus in Côte d'Ivoire: assessment of genotype selection by the isolation method. Infect. Genet. Evol. 3: 143-149.

Jamonneau V, Garcia A, Frézil JL, N'Guessan P, N'Dri L, Laveissière C, Truc P (2000a). Clinical and biological evolution of human trypanosomiasis in Côte d'Ivoire. Ann. Trop. Med. Parasitol. 94: 8, 831-835.

Jamonneau V, Garcia A, Ravel S, Cuny G, Oury B, Solano P, N'Guessan P, N'Dri L, Sanon R, Frézil JL, Truc P (2002). Genetic characterisation of Trypanosoma brucei ssp. and clinical evolution of Human African Trypanosomiasis in Côte d'Ivoire. Trop. Med. Int. Health 7: 610-621.

Jamonneau V, N'Guessan P, N'Dri L, Simarro P, Truc P (2000b). Exploration of the distribution of Trypanosoma brucei ssp. in West Africa, by multilocus enzyme electrophoresis. Ann. Trop. Med. Parasitol. 94: 643-649.

Jamonneau V, Truc P, Büscher P, Magnus E. (2000c). Preliminary evaluation of Latex/T. b. gambiense and alternatives versions of $\mathrm{CATT} / T$. b. gambiense for the serodiagnosis of Human African Trypanosomiasis of a population at risk in Côte d'lvoire: considerations for mass-screening. Acta Trop. 76: 175-183.

Lanham SM, Godfrey DG (1970). Isolation of Salivarian trypanosomes from man and other animals using DEAE-cellulose. Exp. Parasitol., 28, 521-534.

Lejon V, Büscher P, Sema NH, Magnus E, Van Meirvenne N (1998). Human African trypanosomiasis: a latex agglutination field test for quantifying IgM in cerebrospinal. Bull. World Health Organ. 76: 553558.

Lejon V, Legros D, Richer M, Ruiz JA, Jamonneau V, Truc P, Doua F, Djé N, N'Siesi FX, Bisser S, Magnus E, Wouters I, Konings J, Vervoort T, Sultan F, Büscher P (2002). IgM quantification in the cerebrospinal fluid of sleeping sickness patients by a latex card agglutination test. Trop. Med. Int. Health 7: 685-692.

Lumsden WHR, Kimber CD, Evans DA, Doig SJ (1979). Trypanosoma brucei : miniature anion-exchange centrifugation technique for detection of low parasitemias; adaptation for field use. Trans. R. Soc. Trop. Med. Hyg. 73: 312-317.

Magnus E, Vervoort T, Van Meirvenne N (1978). A card-agglutination test with stained trypanosomes (CATT) for the serological diagnosis of T. gambiense trypanosomiasis. Ann. Soc. Belge Méd. Trop. 59: 169-176.

Martin G, Leboeuf A, Roubaud E (1909). Rapport de la mission d'étude de la maladie du sommeil au Congo français, 1906-1908. Masson \& Cie ed., Paris.

Masiga DK, McNamara J, Laveissière C, Truc P, Gibson WC (1996). A high prevalence of mixed trypanosome infections in tsetse flies in Sinfra, Côte d'Ivoire, detected by DNA amplification. Parasitology $112: 75-80$

Mc Namara JJ, Bailey JW, Smith D H, Wakhooli S, Godfrey DG (1995). Isolation of Trypanosoma brucei gambiense from northern Uganda: evaluation of the kit for in vitro isolation (KIVI) in an epidemic focus. Trans. R. Soc. Trop. Med. Hyg. 89: 388-389.

Mehlitz D, Zilmann U, Scott CM, Godfrey DG (1982). Epidemiological studies on the animal reservoir of gambiense sleeping sickness. 3: Characterization of Trypanozoon stocks by isoenzymes and sensitivity to human serum. Tropenmed. Parasit. 33: 113-118.

Morel C (2003). Neglected diseases: under-funded research and inadequate health interventions. EMBO reports, special issue, 4: 3538.

Mulligan H. W. (1970). The African Trypanosomiasis. George Allen and Unwin, ed., London.

Oka-Komoin C, Truc P, Bengaly Z, Formenty P, Duvallet G, Lauginie F, Raath JP, N'Depo AE, Leforban Y (1994). Etude de la prévalence des infections à trypanosomoses chez différentes espèces d'animaux sauvages du Parc National de la Comoé en Côte d'Ivoire: résultats préliminaires sur la comparaison de trois méthodes de diagnostic. Revue Elev. Méd. Vét. Pays Trop. 47: 189-194.

Tibayrenc M, Kjellberg F, Ayala FJ (1990). A clonal theory of parasitic protozoa: the population structures of Entomoeba, Giardia, Leishmania, Naegleria, Plasmodium, Trichomonas and Trypanosoma and their medical and taxonomical consequences. Proc. Natl. Acad Sci. USA, 87: 2414-2418.

Truc P, Aerts D, McNamara JJ, Claes Y, Allingham R, Le Ray D, Godfrey DG (1992). The direct in vitro isolation of Trypanosoma brucei from man and animals, and its potential value for the diagnosis of Gambian trypanosomiasis. Trans. R. Soc. Trop. Med. Hyg. 86: 627-629.

Truc P, Cuny G (2000). Apport de la biologie moléculaire à l'identification des trypanosomes responsables de la Trypanosomiase Humaine Africaine ou maladie du sommeil. Méd. Trop. 60 : 115-119.

Truc P, Cuny G (2001). Répartition et propagation de la Trypanosomiase Humaine Africaine: intérêt de l'identification génétique des trypanosomes. Méd. Trop. 61: 433-436.

Truc P, Formenty P, Diallo PB, Komoin-Oka C, Lauginie F (1997). Confirmation of two distinct classes of zymodemes of Trypanosoma brucei infecting patients and wild mammals in Côte d'lvoire: suspected difference in pathogenicity. Ann. Trop. Med. Parasitol. 91: 951-956.

Truc P, Jamonneau V, Cuny G, Frézil JL (1999). Use of polymerase chain reaction in human African trypanosomiasis stage determination and follow-up. Bull. World Health Organ. 77: 745-48.

Truc $P$, Lejon $V$, Magnus $E$, Jamonneau $V$, Nangouma A, Verloo T, Penchenier L, Büscher $\mathrm{P}$ (2002a). Comparison of the micro-CATT, CATT/T. b. gambiense and LATEX/T. b. gambiense for surveillance and diagnosis of Human African Trypanosomiasis in West and Central Africa. Bull. World Health Organ. 80: 882-886.

Truc P, Lekane Likeufack C, Mbongo N, Ebo'o Enyenga V. A procedure for isolating and freezing metacyclic Trypanosoma brucei gambiense forms in the field. Acta Trop, in press.

Truc P, Mathieu Daudé F, Tibayrenc M (1991). Multilocus isoenzyme identification of Trypanosoma brucei stocks isolated in Central Africa: evidence for an animal reservoir of sleeping sickness in Congo. Acta Trop. 49: 127-135.

Truc P, Ravel S, Jamonneau V, N'Guessan P, Cuny G (2002b). Genetic variability within Trypanosoma brucei gambiense and co-infections by different genotypes in Human African Trypanosomiasis patients in Côte d'Ivoire. Trans. R. Soc. Trop. Med. Hyg. 96: 52-55.

Truc P, Tibayrenc M (1993). Population genetics of Trypanosoma brucei in Central Africa: taxonomic and epidemiological significance. Parasitology 106: 137-149.

Van Nieuwenhove S (1999). Present strategies in the treatment of human African trypanosomiasis. In : "Progress in Human African Trypanosomiasis sleeping sickness", Editors M. Dumas, B. Bouteille, A. Buguet, Springer Publ. Paris, pp. 253-280.

Woo PTK (1970). The haematocrit centrifuge technique for the diagnosis of African trypanosomiasis. Acta Trop. 27: 384-386.

World Health Organization, 1998. Control and surveillance of African trypanosomiasis. WHO Technical Series 881, $113 \mathrm{p}$. 